\title{
Three Acylated Glycosidic Acid Methyl Esters and Two Acylated Methyl Glycosides Generated from the Convolvulin Fraction of Seeds of Quamoclit pennata by Treatment with Indium(III) Chloride in Methanol
}

\author{
Kousuke Akiyama, ${ }^{a}$ Tomoko Mineno, ${ }^{b}$ Masafumi Okawa, ${ }^{c}$ Junei Kinjo, ${ }^{c}$ Hiroyuki Miyashita, ${ }^{d}$ \\ Hitoshi Yoshimitsu, ${ }^{d}$ Toshihiro Nohara, ${ }^{d}$ and Masateru Ono ${ }^{*, a}$ \\ ${ }^{a}$ School of Agriculture, Tokai University; 5435 Minamiaso, Aso, Kumamoto 869-1404, Japan: ${ }^{b}$ Faculty of \\ Pharmacy, Takasaki University of Health and Welfare; 60 Nakaorui, Takasaki, Gunma 370-0033, Japan: ${ }^{c}$ Faculty \\ of Pharmaceutical Sciences, Fukuoka University; 8-19-1 Nanakuma, Jonan-ku, Fukuoka 814-0180, Japan: and \\ ${ }^{d}$ Faculty of Pharmaceutical Sciences, Sojo University; 4-22-2 Ikeda, Nishi-ku, Kumamoto 860-0082, Japan. \\ Received May 8, 2013; accepted June 8, 2013
}

Treatment of the ether-insoluble resin glycoside (convolvulin) fraction from seeds of Quamoclit pennata (Convolvulaceae) with indium(III) chloride in methanol provided three oligoglycosides of hydroxy fatty acid (glycosidic acid) methyl esters and two methyl glycosides, which were partially acylated by a glycosidic acid, $7 S$-hydroxydecanoic acid 7-O- $\beta$-D-quinovopyranoside (quamoclinic acid B) and/or two organic acids, (E)-2-methylbut-2-enoic (tiglic) acid and/or $3 R$-hydroxy-2R-methylbutyric (nilic) acid. Their structures were elucidated on the basis of spectroscopic data and chemical conversions.

Key words resin glycoside; convolvulin; Quamoclit pennata; acylated glycosidic acid methyl ester; acylated methyl glycoside; indium(III) chloride

The so-called resin glycosides, which are commonly found in plants of the Convolvulaceae family, are well known as purgatives, and are characteristic ingredients of crude drugs such as Pharbitis Semen (the seed of Pharbitis nil CHOISY), Mexican Scammoniae Radix (the root of Convolvulus scammonia L.), Orizabae Tuber (the tuber of Ipomoea orizabensis (PELLET) Ledanois), Jalapae Tuber (the tuber of I. purga Hayne), and Rhizoma Jalapae Braziliensis (the root of I. operculata (Gomes) MART.). ${ }^{1)}$ They can be roughly divided into an ethersoluble resin glycoside called jalapin, and an ether-insoluble one called convolvulin. ${ }^{2)}$ In 1987 , Noda et al. succeeded in the isolation and structural elucidation of four jalapins. ${ }^{3)}$ Almost all jalapins hitherto isolated and characterized had common intramolecular macrocyclic ester structures composed of an oligoglycoside of a hydroxy fatty acid partially acylated by some organic acids at the sugar moiety (acylated glycosidic acid); some examples were ester-type dimers. ${ }^{4-9)}$ On the other hand, convolvulin is regarded as an oligomer of various of acylated glycosidic acids. ${ }^{10)}$ However, no pure convolvulin has thus far been isolated, and chemical studies had been confined only to characterization of the component organic acids and glycosidic acids afforded by alkaline hydrolysis of mixtures of convolvulins. ${ }^{11-15)}$ We recently reported the isolation and structural elucidation of seven acylated glycosidic acid methyl ester monomers that were generated by treatment of the crude convolvulin fraction (named pharbitin) from Pharbitis Semen using indium(III) chloride in methanol $(\mathrm{MeOH}),{ }^{16)}$ which was reported by Mineno and Kansui ${ }^{17)}$ to be a catalyst for mild methyl esterification of carboxylic acids.

Quamoclit pennata BoJer is a Convolvulaceae plant native to tropical regions of South America, and is primarily cultivated as an ornamental plant. We previously reported the isolation and structural elucidation of a glycosidic acid called quamoclinic acid $\mathrm{A}$, which was obtained along with three organic acids, $2 S$-methylbutyric, $n$-decanoic, and $n$-dodecanoic

The authors declare no conflict of interest. acids, upon alkaline hydrolysis of the crude jalapin fraction of the plant seeds. ${ }^{18)} \mathrm{We}$ also isolated six genuine jalapins, quamoclins I, II, III, IV, V, and VI from the fraction. ${ }^{18,19)}$ In the case of convolvulins from the seeds, we recently reported the structures of seven glycosidic acids, quamoclinic acids $\mathrm{B}, \mathrm{C}, \mathrm{D}, \mathrm{E}, \mathrm{F}, \mathrm{G}$, and $\mathrm{H}$, and six organic acids, isobutyric, $2 S$-methylbutyric, $(E)$-2-methylbut-2-enoic (tiglic), 3Rhydroxy-2R-methylbutyric ( $2 R, 3 R$-nilic), $7 S$-hydroxydecanoic, and $7 S$-hydroxydodecanoic acids, which were obtained by alkaline hydrolysis of the crude convolvulin fraction of the seeds. ${ }^{14,15}$ As part of an ongoing study of the resin glycosides from these seeds, this paper reports the isolation and structural elucidation of three acylated glycosidic acid methyl esters and two acylated methyl glycosides, which were generated by treatment of the crude convolvulin fraction with indium(III) chloride in $\mathrm{MeOH}$.

\section{Results and Discussion}

Despite numerous attempts, the isolation of pure resin glycosides from the crude convolvulin fraction ${ }^{19)}$ of the seeds of $Q$. pennata has been unsuccessful. This fraction was therefore treated with indium(III) chloride in $\mathrm{MeOH}$, as in the case of pharbitin. ${ }^{16)}$ The treated fraction exhibited a number of separate spots in TLC on silica gel. This treated fraction was successively subjected to Diaion HP20, Sephadex LH-20, silica gel, and Chromatorex ODS column chromatography, and HPLC on octadecyl silica (ODS), to afford five compounds, temporarily referred to as QM-1 (1)-QM-5 (5).

QM-1 (1) was obtained as an amorphous powder and exhibited a $[\mathrm{M}-\mathrm{H}]^{-}$ion peak at $\mathrm{m} / z 1509$ in negative-ion FAB-MS and a $[\mathrm{M}+\mathrm{Na}]^{+}$ion peak at $\mathrm{m} / \mathrm{z} 1533$ in positiveion FAB-MS. High-resolution (HR)-positive-ion FAB-MS indicated the molecular formula of $\mathbf{1}$ to be $\mathrm{C}_{67} \mathrm{H}_{114} \mathrm{O}_{37}$. On alkaline hydrolysis, $\mathbf{1}$ furnished an organic acid fraction and a glycosidic acid. GC of the former revealed the presence of nilic acid and tiglic acid. The latter was identified as quamoclinic acid F (6) by comparison of the ${ }^{1} \mathrm{H}-\mathrm{NMR}$ spectrum 
with that of an authentic sample. ${ }^{14)}$ The ${ }^{1} \mathrm{H}-\mathrm{NMR}$ spectrum of 1 showed signals due to $\mathrm{H}-2[\delta 2.90(1 \mathrm{H}, \mathrm{dq}, J=7.0,7.0 \mathrm{~Hz})]$ of the first niloyl unit (Nla), H-3 $[\delta 7.04(1 \mathrm{H}$, brq, $J=7.0 \mathrm{~Hz})]$ of the tigloyl unit (Tig), one methoxy group $[\delta 3.63(3 \mathrm{H}, \mathrm{s})]$, one primary methyl group $[\delta 0.90(3 \mathrm{H}, \mathrm{t}, J=7.0 \mathrm{~Hz})]$, two nonequivalent methylene protons $[\delta 2.72(1 \mathrm{H}, \mathrm{dd}, J=6.5,15.0 \mathrm{~Hz})$, $2.69(1 \mathrm{H}, \mathrm{dd}, J=4.5,15.0 \mathrm{~Hz})]$ adjacent to a carbonyl group, seven anomeric protons $[\delta 6.26(1 \mathrm{H}, \mathrm{s}), 6.20(1 \mathrm{H}, \mathrm{d}, J=7.5 \mathrm{~Hz})$, $6.03(1 \mathrm{H}, \mathrm{s}), 5.92(1 \mathrm{H}, \mathrm{d}, J=8.0 \mathrm{~Hz}), 5.61(1 \mathrm{H}, \mathrm{d}, J=7.5 \mathrm{~Hz})$, $5.06(1 \mathrm{H}, \mathrm{d}, J=8.0 \mathrm{~Hz}), 4.80(1 \mathrm{H}, \mathrm{d}, J=7.0 \mathrm{~Hz})]$, eight secondary methyl groups $[\delta 1.88(3 \mathrm{H}, \mathrm{d}, J=6.5 \mathrm{~Hz}), 1.73(3 \mathrm{H}$, $\mathrm{d}, J=7.0 \mathrm{~Hz}), 1.54(3 \mathrm{H}, \mathrm{d}, J=6.0 \mathrm{~Hz}), 1.53(3 \mathrm{H}, \mathrm{d}, J=6.0 \mathrm{~Hz})$, $1.45(3 \mathrm{H}, \mathrm{d}, J=6.0 \mathrm{~Hz}), 1.42(3 \mathrm{H}, \mathrm{d}, J=6.5 \mathrm{~Hz}), 1.39(3 \mathrm{H}, \mathrm{d}$, $J=6.5 \mathrm{~Hz}), 1.33(3 \mathrm{H}, \mathrm{d}, J=7.0 \mathrm{~Hz})]$, and one tertiary methyl group $[\delta 1.97(3 \mathrm{H}$, br s) $]$ (Table 1$)$. The ${ }^{13} \mathrm{C}-\mathrm{NMR}$ spectrum of 1 yielded signals due to 67 carbons, including seven anomeric carbons $(\delta 106.1,102.5,102.3,102.2,102.1,101.6,101.0)$, two olefinic carbons $(\delta 138.0,128.9)$, and three carboxyl carbons $(\delta$ 175.4, 172.9, 167.1) (Table 2). These ${ }^{1} \mathrm{H}$ - and ${ }^{13} \mathrm{C}$-NMR signals were assigned on the basis of ${ }^{1} \mathrm{H}-{ }^{1} \mathrm{H}$ correlation spectroscopy (COSY), heteronuclear multiple-quantum coherence (HMQC), heteronuclear multiple-bond correlation (HMBC), and 1Dtotal correlation spectroscopy (TOCSY) spectra, and indicated that 1 contains $1 \mathrm{~mol}$ each of nilic acid, tiglic acid, and 6 . A comparison of the chemical shifts of the ${ }^{1} \mathrm{H}-\mathrm{NMR}$ signals ${ }^{14)}$ due to the sugar moieties between $\mathbf{1}$ and $\mathbf{6}$ showed that the signals due to $\mathrm{H}-4$ of the first quinovosyl unit (Qui) and H-4 of the second quinovosyl unit (Qui') of 1 showed significant downfield shifts of $1.58 \mathrm{ppm}$ and $1.67 \mathrm{ppm}$, respectively, as a result of acylation. These data indicated that the ester linkages were located at $\mathrm{OH}-4$ of Qui and $\mathrm{OH}-4$ of Qui'. The sites of each ester linkage of Nla and Tig were determined from the HMBC spectrum of $\mathbf{1}$, with key cross-peaks observed between H-4 of Qui and C-1 of Nla, H-4 of Qui' and C-1 of Tig, and methoxy protons and $\mathrm{C}-1$ of the aglycone moiety (Agl) (Fig. 1). Therefore, Nla and Tig were attached to OH-4 of Qui and OH-4 of Qui', respectively. The configuration of the nilic acid unit of this crude convolvulin fraction was previously determined to be $2 R, 3 R .^{14)}$ Consequently, the structure of $\mathbf{1}$ was defined as methyl $3 S, 11 S$-dihydroxytetradecanoate $11-O-\alpha$-L-rhamnopyranosyl-(1 $\rightarrow 3)-O$-(4-O-tigloyl)$\beta$-D-quinovopyranosyl-( $1 \rightarrow 2)-O$ - $\beta$-D-glucopyranosyl- $(1 \rightarrow$ $3)$-[O-(4-O-2R,3R-niloyl)- $\beta$-D-quinovopyranosyl- $(1 \rightarrow 4)]-O-\alpha$ L-rhamnopyranosyl- $(1 \rightarrow 2)-O$ - $\beta$-D-glucopyranosyl- $(1 \rightarrow 2)-\beta$-Dfucopyranoside (Fig. 2).

QM-2 (2) was obtained as an amorphous powder, and afforded tiglic acid, nilic acid, 6 , and quamoclinic acid B $(7)^{14)}$ on alkaline hydrolysis. Its positive-ion FAB-MS indicated a $[\mathrm{M}+\mathrm{Na}]^{+}$ion peak at $m / z 1849$, which was 316 mass units [quamoclinic acid $\mathrm{B}$ unit $(\mathrm{QaB})$ ] lager than that of $\mathbf{1}$. The molecular formula of 2 was found to be $\mathrm{C}_{83} \mathrm{H}_{142} \mathrm{O}_{43}$ by HRpositive-ion FAB-MS. The ${ }^{1} \mathrm{H}$ - and ${ }^{13} \mathrm{C}-\mathrm{NMR}$ spectra of $\mathbf{2}$ were analogous to those of $\mathbf{1}$, except for the appearance of signals due to one $\mathrm{QaB}$ (Tables 1, 2). Thus, 2 is composed of $1 \mathrm{~mol}$ each of nilic acid, tiglic acid, 6, and 7. The ${ }^{1} \mathrm{H}-\mathrm{NMR}$ signals due to the sugar moiety of $\mathbf{2}$ were compared with those of 1 , and the signal due to $\mathrm{H}-2$ of the rhamnosyl unit (Rha) of 2 showed a downfield shift of $1.15 \mathrm{ppm}$. On the other hand, the signals due to H-4 of Qui and H-4 of Qui' of 2 were observed at similar chemical shifts to those of $\mathbf{1}$. From these data, $\mathbf{2}$ was assumed to be a derivative of $\mathbf{1}$, in which 7 was attached to
OH-2 of Rha of $\mathbf{1}$. In the HMBC spectrum of 2, cross-peaks were observed between H-4 of Qui or H-4 of Qui' and C-1 of Nla, H-4 of Qui' or H-4 of Qui and C-1 of Tig, and methoxy protons and $\mathrm{C}-1$ of $\mathrm{Agl}$ (Fig. 1). However, the counterparts of C-1 of Nla and C-1 of Tig could not be identified because the ${ }^{1} \mathrm{H}-\mathrm{NMR}$ signals due to H-4 of Qui and H-4 of Qui' appeared at almost the same chemical shifts. Although no cross-peak between H-2 of Rha and C-1 of QaB was observed in the HMBC spectrum of $\mathbf{2}$, the above data suggested that QaB was attached to $\mathrm{OH}-2$ of Rha.

To determine the sites of each ester linkage of Nla and Tig, partial deacylation of $\mathbf{2}$ was conducted. Compound $\mathbf{2}$ was refluxed with $5 \%$ triethylamine-MeOH for $1 \mathrm{~h}$, and the products were purified by HPLC to give $\mathbf{8}$. The positive-ion FAB-MS of 8 showed a $[\mathrm{M}+\mathrm{Na}]^{+}$ion peak at $\mathrm{m} / z$ 1749, which was 100 mass units (niloyl unit) smaller than that of 2 . In the ${ }^{1} \mathrm{H}-\mathrm{NMR}$ spectrum of $\mathbf{8}$, the signal due to $\mathrm{H}-4$ of Qui was shifted upfield (1.66 ppm) compared with that of $\mathbf{2}$, and the signals due to the nilic acid unit disappeared; however, the signals due to H-4 of Qui' and H-2 of Rha were observed at quite similar chemical shifts to those of 2 (Table 1). Also, a key correlation was observed between $\mathrm{H}-4$ of Qui' and C-1 of Tig in the HMBC spectrum of $\mathbf{8}$. These data suggested that Nla and Tig of $\mathbf{2}$ were located at OH-4 of Qui and OH-4 of Qui', respectively. Accordingly, the structures of $\mathbf{2}$ and $\mathbf{8}$ were respectively defined as methyl $3 S, 11 S$-dihydroxytetradecanoate $11-O$ - $\alpha$-L-rhamnopyranosyl-(1 $\rightarrow 3)-O$-(4- $O$-tigloyl)$\beta$-D-quinovopyranosyl-( $1 \rightarrow 2)-O-\beta$-D-glucopyranosyl- $(1 \rightarrow$ $3)$ - $[O-(4-O-2 R, 3 R$-niloyl)- $\beta$-D-quinovopyranosyl-( $1 \rightarrow 4)]-O$ (2-O-7S-hydroxydecanoyl $7-O-\beta$-D-quinovopyranoside)- $\alpha$-Lrhamnopyranosyl-( $1 \rightarrow 2)-O$ - $\beta$-D-glucopyranosyl- $(1 \rightarrow 2)-\beta$-Dfucopyranoside and its deacyl derivative, in which Nla of 2 was cleaved (Fig. 2).

QM-3 (3) was obtained as an amorphous powder, and HR-positive-ion FAB-MS showed that its molecular formula was found to be the same as that of 2 . On alkaline hydrolysis, 3 furnished nilic acid, tiglic acid, 7, and quamoclinic acid E (9). ${ }^{14)}$ The ${ }^{1} \mathrm{H}$ - and ${ }^{13} \mathrm{C}-\mathrm{NMR}$ spectra of $\mathbf{3}$ had signals due to one each of methoxy group, Nla, Tig, QaB, and quamoclinic acid $\mathrm{E}$ unit (Tables 1,2). Comparison of the ${ }^{1} \mathrm{H}-\mathrm{NMR}$ signals ${ }^{14)}$ due to the sugar moiety in $\mathbf{3}$ and $\mathbf{9}$ indicated acylation shifts $[\Delta \delta=\delta(\mathbf{3})-\delta(\mathbf{9})]$ of the signals due to $\mathrm{H}-2(\Delta \delta=1.11)$ of Rha, H-4 $(\Delta \delta=1.64)$ of the second fucosyl unit $\left(\mathrm{Fuc}^{\prime}\right)$, and H-4 $(\Delta \delta=1.79)$ of Qui'. In addition, the HMBC spectrum of 3 showed cross-peaks between $\mathrm{H}-4$ of Fuc' and C-1 of Nla, H-4 of Qui' and C-1 of Tig, and the methoxy protons and C-1 of Agl (Fig. 1). Accordingly, the structure of 3 was assigned as methyl $3 S, 11 S$-dihydroxytetradecanoate $\quad 11-O$ - $\beta$-D-fucopyranosyl-( $1 \rightarrow 3)-O$-(4- $O$-tigloyl)- $\beta$ D-quinovopyranosyl- $(1 \rightarrow 2)-O-\beta$-D-glucopyranosyl- $(1 \rightarrow 3)$ $[O-(4-O-2 R, 3 R$-niloyl $)-\beta$-D-fucopyranosyl- $(1 \rightarrow 4)]-O-(2-O$ $7 S$-hydroxydecanoyl 7-O- $\beta$-D-quinovopyranoside)- $\alpha$-L-rhamnopyranosyl- $(1 \rightarrow 2)-O$ - $\beta$-D-glucopyranosyl- $(1 \rightarrow 2)-\beta$-D-fucopyranoside (Fig. 2).

QM-4 (4) was obtained as an amorphous powder. Negative-ion FAB-MS and positive-ion FAB-MS of $\mathbf{4}$ showed a $[\mathrm{M}-\mathrm{H}]^{-}$ion peak at $\mathrm{m} / \mathrm{z} 1139$ and a $[\mathrm{M}+\mathrm{Na}]^{+}$ion peak at $\mathrm{m} / \mathrm{z}$ 1163 , respectively, indicating its molecular weight to be 1140 . The molecular formula of $\mathbf{4}$ was shown by HR-positive-ion FAB-MS to be $\mathrm{C}_{47} \mathrm{H}_{80} \mathrm{O}_{31}$. The ${ }^{1} \mathrm{H}-\mathrm{NMR}$ spectrum of $\mathbf{4}$ showed signals due to two $\mathrm{H}-2$ of niloyl units, one methoxy group, 
Table 1. ${ }^{1} \mathrm{H}-\mathrm{NMR}$ Spectral Data for $\mathbf{1}-\mathbf{3}$ and 8 (in Pyridine- $d_{5}, 500 \mathrm{MHz}$ )

\begin{tabular}{|c|c|c|c|c|}
\hline Position & 1 & 2 & 8 & 3 \\
\hline Fuc-1 & $4.80 \mathrm{~d}(7.0)$ & $4.82 \mathrm{~d}(7.0)$ & $4.85 \mathrm{~d}(7.5)$ & $4.79 \mathrm{~d}(7.5)$ \\
\hline 2 & $4.47^{a)}$ & $4.48 \mathrm{dd}(7.0,8.5)$ & $4.51 \mathrm{dd}(7.5,8.5)$ & $4.47 \mathrm{dd}(7.5,9.0)$ \\
\hline 3 & $4.48^{a)}$ & $4.51 \mathrm{dd}(3.5,8.5)$ & $4.58^{a)}$ & $4.50 \mathrm{dd}(3.0,9.0)$ \\
\hline 4 & 4.06 brs & 4.10 brd (3.5) & $4.14^{a)}$ & $4.08 \mathrm{dd}(3.0)$ \\
\hline 5 & $3.92^{a)}$ & $3.96^{a)}$ & $4.04^{a)}$ & $3.95^{a)}$ \\
\hline 6 & $1.39 \mathrm{~d}(6.5)$ & $1.37 \mathrm{~d}(6.5)$ & $1.41 \mathrm{~d}(6.5)$ & $1.44 \mathrm{~d}(6.5)$ \\
\hline Fuc' $^{\prime} 1$ & & & & $5.86 \mathrm{~d}(8.0)$ \\
\hline 2 & & & & $4.20 \mathrm{dd}(8.0,9.0)$ \\
\hline 3 & & & & $4.36 \mathrm{dd}(3.0,9.0)$ \\
\hline 4 & & & & $5.62 \mathrm{~d}(3.0)$ \\
\hline 5 & & & & $4.34^{a)}$ \\
\hline 6 & & & & $1.48 \mathrm{~d}(6.5)$ \\
\hline Fuc"-1 & & & & $4.93 \mathrm{~d}(7.5)$ \\
\hline 2 & & & & $4.20 \mathrm{dd}(7.5,9.0)$ \\
\hline 3 & & & & $4.02 \mathrm{dd}(3.0,9.0)$ \\
\hline 4 & & & & $3.95 \mathrm{~d}(3.0)$ \\
\hline 5 & & & & $3.77^{a)}$ \\
\hline 6 & & & & $1.44 \mathrm{~d}(6.5)$ \\
\hline Glc-1 & $5.61 \mathrm{~d}(7.5)$ & $5.59 \mathrm{~d}(8.0)$ & $5.67 \mathrm{~d}(7.5)$ & $5.59 \mathrm{~d}(8.0)$ \\
\hline 2 & $4.18 \mathrm{dd}(7.5,9.0)$ & $4.18 \mathrm{dd}(8.0,9.0)$ & $4.21 \mathrm{dd}(7.5,9.0)$ & $4.18^{a)}$ \\
\hline 3 & $4.13 \mathrm{dd}(9.0,9.0)$ & $4.10 \mathrm{dd}(9.0,9.0)$ & $4.11 \mathrm{dd}(9.0,9.0)$ & $4.09 \mathrm{dd}(9.0,9.0)$ \\
\hline 4 & $4.04 \mathrm{dd}(9.0,9.0)$ & $4.01 \mathrm{dd}(9.0,9.0)$ & $4.02^{a)}$ & $4.02 \mathrm{dd}(9.0,9.0)$ \\
\hline 5 & $3.60 \mathrm{~m}$ & 3.55 ddd $(3.0,5.5,9.0)$ & 3.58 ddd $(3.0,5.0,9.0)$ & 3.56 ddd $(3.0,5.0,9.0)$ \\
\hline 6 & $4.28 \mathrm{dd}(3.5,11.5)$ & $4.28 \mathrm{dd}(3.0,11.5)$ & $4.29 \mathrm{dd}(3.0,11.5)$ & $4.29 \mathrm{dd}(3.0,11.0)$ \\
\hline 6 & $4.19 \mathrm{dd}(5.0,11.5)$ & $4.16 \mathrm{dd}(5.5,11.5)$ & $4.20^{a)}$ & $4.18^{a)}$ \\
\hline $\mathrm{Glc}^{\prime}-1$ & $6.20 \mathrm{~d}(7.5)$ & $6.14 \mathrm{~d}(7.5)$ & $6.26 \mathrm{~d}(8.0)$ & $6.13 \mathrm{~d}(7.5)$ \\
\hline 2 & $3.94 \mathrm{dd}(7.5,9.0)$ & $3.96 \mathrm{dd}(7.5,9.0)$ & $3.97^{a)}$ & $3.95^{a)}$ \\
\hline 3 & $4.43 \mathrm{dd}(9.0,9.0)$ & $4.38 \mathrm{dd}(9.0,9.0)$ & $4.43 \mathrm{dd}(9.0,9.0)$ & $4.36 \mathrm{dd}(9.0,9.0)$ \\
\hline 4 & $4.10 \mathrm{dd}(9.0,9.0)$ & $4.01 \mathrm{dd}(9.0,9.0)$ & $3.99^{a)}$ & $4.01 \mathrm{dd}(9.0,9.0)$ \\
\hline 5 & $4.01 \mathrm{~m}$ & $3.96 \mathrm{~m}$ & $4.04^{a)}$ & $3.95^{a)}$ \\
\hline 6 & $4.48 \mathrm{dd}(2.5,11.5)$ & 4.47 brd (11.0) & $4.51 \mathrm{dd}(1.5,12.0)$ & $4.44 \mathrm{dd}(2.0,12.0)$ \\
\hline 6 & $4.17 \mathrm{dd}(6.0,11.5)$ & $4.12 \mathrm{dd}(5.5,11.0)$ & $4.14^{a)}$ & $4.11 \mathrm{dd}(5.5,12.0)$ \\
\hline Rha-1 & $6.26 \mathrm{~s}$ & $6.29 \mathrm{~d}(1.5)$ & $6.34 \mathrm{~d}(1.5)$ & $6.27 \mathrm{~d}(1.0)$ \\
\hline 2 & $4.89 \mathrm{brs}$ & $6.04 \mathrm{dd}(1.5,3.0)$ & $6.00 \mathrm{dd}(1.5,3.5)$ & $6.06 \mathrm{dd}(1.0,3.5)$ \\
\hline 3 & $5.18 \mathrm{dd}(3.0,9.0)$ & $5.36 \mathrm{dd}(3.0,9.0)$ & $5.41 \mathrm{dd}(3.5,9.5)$ & $5.36 \mathrm{dd}(3.5,9.5)$ \\
\hline 4 & $4.69 \mathrm{dd}(9.0,9.0)$ & $4.53 \mathrm{dd}(9.0,9.0)$ & $4.59 \mathrm{dd}(9.5,9.5)$ & $4.55 \mathrm{dd}(9.5,9.5)$ \\
\hline 5 & $4.97 \mathrm{dq}(9.0,6.5)$ & $5.03 \mathrm{dq}(9.0,6.0)$ & $5.08 \mathrm{dq}(9.5,6.5)$ & $5.03 \mathrm{dq}(9.5,6.0)$ \\
\hline 6 & $1.88 \mathrm{~d}(6.5)$ & $1.88 \mathrm{~d}(6.0)$ & $1.94 \mathrm{~d}(6.5)$ & $1.89 \mathrm{~d}(6.0)$ \\
\hline Rha'-1 & $6.03 \mathrm{~s}$ & $6.11 \mathrm{dd}(1.5)$ & $6.08 \mathrm{~s}$ & \\
\hline 2 & $4.57 \mathrm{brs}$ & $4.58 \mathrm{dd}(1.5,3.0)$ & $4.57^{a)}$ & \\
\hline 3 & $4.30 \mathrm{dd}(2.5,9.5)$ & $4.31 \mathrm{dd}(3.0,9.0)$ & $4.34 \mathrm{dd}(3.0,9.0)$ & \\
\hline 4 & $4.18 \mathrm{dd}(9.5,9.5)$ & $4.18 \mathrm{dd}(9.0,9.0)$ & $4.19 \mathrm{dd}(9.0,9.0)$ & \\
\hline 5 & $4.08 \mathrm{dq}(9.5,6.0)$ & $4.11 \mathrm{~m}$ & $4.15^{a)}$ & \\
\hline 6 & $1.54 \mathrm{~d}(6.0)$ & $1.56 \mathrm{~d}(6.0)$ & $1.58 \mathrm{~d}(6.0)$ & \\
\hline Qui-1 & $5.92 \mathrm{~d}(8.0)$ & $6.01 \mathrm{~d}(8.0)$ & $5.94 \mathrm{~d}(8.0)$ & \\
\hline 2 & $3.98 \mathrm{dd}(8.0,9.5)$ & $3.99 \mathrm{dd}(8.0,9.0)$ & $3.98^{a)}$ & \\
\hline 3 & $4.34 \mathrm{dd}(9.5,9.5)$ & $4.40 \mathrm{dd}(9.0,9.0)$ & $4.25 \mathrm{dd}(9.0,9.0)$ & \\
\hline 4 & $5.34 \mathrm{dd}(9.5,9.5)$ & $5.36 \mathrm{dd}(9.0,9.0)$ & $3.70 \mathrm{dd}(9.0,9.0)$ & \\
\hline 5 & $4.22 \mathrm{dq}(9.5,6.5)$ & $4.35 \mathrm{~m}$ & $4.15^{a)}$ & \\
\hline 6 & $1.53 \mathrm{~d}(6.5)$ & $1.63 \mathrm{~d}(6.0)$ & $1.70 \mathrm{~d}(6.0)$ & \\
\hline Qui'-1 & $5.06 \mathrm{~d}(8.0)$ & $5.17 \mathrm{~d}(8.0)$ & $5.12 \mathrm{~d}(8.0)$ & $5.22 \mathrm{~d}(8.0)$ \\
\hline 2 & $4.06 \mathrm{dd}(8.0,9.5)$ & $4.15 \mathrm{dd}(8.0,9.5)$ & $3.97^{a)}$ & $4.04 \mathrm{dd}(8.0,9.5)$ \\
\hline 3 & $4.16 \mathrm{dd}(9.5,9.5)$ & $4.42 \mathrm{dd}(9.5,9.5)$ & $4.39 \mathrm{dd}(9.5,9.5)$ & $4.30 \mathrm{dd}(9.5,9.5)$ \\
\hline 4 & $5.26 \mathrm{dd}(9.5,9.5)$ & $5.36 \mathrm{dd}(9.5,9.5)$ & $5.33 \mathrm{dd}(9.5,9.5)$ & $5.31 \mathrm{dd}(9.5,9.5)$ \\
\hline 5 & $3.85 \mathrm{dq}(9.5,6.0)$ & $4.02 \mathrm{~m}$ & $4.04^{a)}$ & $4.02 \mathrm{dq}(9.5,6.0)$ \\
\hline 6 & $1.45 \mathrm{~d}(6.0)$ & $1.64 \mathrm{~d}(6.5)$ & $1.66 \mathrm{~d}(6.0)$ & $1.63 \mathrm{~d}(6.0)$ \\
\hline Agl-2 & $2.72 \mathrm{dd}(8.0,14.5)$ & $2.73 \mathrm{dd}(8.0,15.0)$ & $2.73 \mathrm{dd}(8.0,14.5)$ & $2.73 \mathrm{dd}(8.0,15.0)$ \\
\hline 2 & $2.69 \mathrm{dd}(4.5,14.5)$ & $2.69 \mathrm{dd}(5.0,15.0)$ & $2.69 \mathrm{dd}(5.0,14.5)$ & $2.69 \mathrm{dd}(5.0,15.0)$ \\
\hline 3 & $4.41^{a)}$ & $4.40^{a)}$ & $4.41^{a)}$ & $4.40 \mathrm{~m}$ \\
\hline
\end{tabular}


Table 1. Continued

\begin{tabular}{|c|c|c|c|c|}
\hline Position & 1 & 2 & 8 & 3 \\
\hline 11 & $3.88^{a)}$ & $3.89^{a)}$ & $3.88 \mathrm{~m}$ & $3.87^{a)}$ \\
\hline 14 & $0.90 \mathrm{t}(7.0)$ & $0.90 \mathrm{t}(7.5)$ & $0.89 \mathrm{t}(7.0)$ & $0.93 \mathrm{t}(7.0)$ \\
\hline $\mathrm{OCH}_{3}$ & $3.63 \mathrm{~s}$ & $3.63 \mathrm{~s}$ & $3.63 \mathrm{~s}$ & $3.63 \mathrm{~s}$ \\
\hline Nla-2 & $2.90 \mathrm{dq}(7.0,7.0)$ & $2.91 \mathrm{dq}(7.0,7.0)$ & & $2.79 \mathrm{dq}(7.5,7.5)$ \\
\hline 3 & $4.42^{a)}$ & $4.35^{a)}$ & & $4.27^{a)}$ \\
\hline 4 & $1.42 \mathrm{~d}(6.5)$ & $1.43 \mathrm{~d}(6.5)$ & & $1.39 \mathrm{~d}(6.5)$ \\
\hline 5 & $1.33 \mathrm{~d}(7.0)$ & $1.34 \mathrm{~d}(7.0)$ & & $1.30 \mathrm{~d}(7.5)$ \\
\hline Tig-3 & 7.04 brq $(7.0)$ & $7.10 \mathrm{qq}(1.5,7.5)$ & $7.11 \mathrm{q}(7.0)$ & 7.13 qq $(1.0,7.5)$ \\
\hline 4 & $1.73 \mathrm{~d}(7.0)$ & $1.76 \mathrm{~d}(7.5)$ & $1.77 \mathrm{~d}(7.0)$ & $1.73 \mathrm{~d}(7.5)$ \\
\hline 5 & 1.97 brs & $2.01 \mathrm{brs}$ & $2.03 \mathrm{brs}$ & 1.97 brs \\
\hline QaB-2 & & 2.50 ddd $(8.0,8.0,16.0)$ & $2.52^{a)}$ & 2.51 ddd $(7.5,7.5,16.0)$ \\
\hline 2 & & 2.45 ddd $(8.0,8.0,16.0)$ & $2.49^{a)}$ & 2.45 ddd $(7.5,7.5,16.0)$ \\
\hline 7 & & $3.90^{a)}$ & $3.91 \mathrm{~m}$ & $3.89^{a)}$ \\
\hline 10 & & $0.96 \mathrm{t}(7.5)$ & $0.96 \mathrm{t}(7.0)$ & $0.96 \mathrm{t}(7.0)$ \\
\hline Qui"-1 & & $4.79 \mathrm{~d}(8.0)$ & $4.80 \mathrm{~d}(7.5)$ & $4.79 \mathrm{~d}(7.5)$ \\
\hline 2 & & $3.96 \mathrm{dd}(8.0,9.0)$ & $3.97^{a)}$ & $3.95 \mathrm{dd}(7.5,9.0)$ \\
\hline 3 & & $4.14 \mathrm{dd}(9.0,9.0)$ & $4.15^{a)}$ & $4.14 \mathrm{dd}(9.0,9.0)$ \\
\hline 4 & & $3.71 \mathrm{dd}(9.0,9.0)$ & $3.72 \mathrm{dd}(9.0,9.0)$ & $3.71 \mathrm{dd}(9.0,9.0)$ \\
\hline 5 & & $3.78 \mathrm{dq}(9.0,6.0)$ & $3.79 \mathrm{dq}(9.0,6.5)$ & $3.78 \mathrm{dq}(9.0,6.0)$ \\
\hline 6 & & $1.63 \mathrm{~d}(6.0)$ & $1.63 \mathrm{~d}(6.5)$ & $1.63 \mathrm{~d}(6.0)$ \\
\hline
\end{tabular}

$\delta$ in ppm from TMS. Coupling constants $(J)$ in $\mathrm{Hz}$ are given in parentheses. $a$ ) Signals were overlapped with other signals.

six anomeric protons, and eight secondary methyl groups and its ${ }^{13} \mathrm{C}$-NMR spectrum exhibited signals due to six anomeric carbons and two carboxyl carbons (Tables 3,4). However, no signals attributable to a hydroxy fatty acid, which is the aglycone unit of resin glycosides, were observed. From the assigned data, it was considered that $\mathbf{4}$ was a methyl hexaglycoside esterified by two nilic acids. On alkaline hydrolysis, 4 furnished nilic acid and a methyl glycoside (10), temporarily referred to as methyl quamoside A. The negative-ion FAB-MS of 10 showed a $[\mathrm{M}-\mathrm{H}]^{-}$ion peak at $\mathrm{m} / \mathrm{z} 939$ along with fragment ion peaks at $\mathrm{m} / \mathrm{z} 793$ [939-146 (6-deoxyhexosyl unit)] 631 [793-162 (hexosyl unit) $]^{-}, 485[631-146]^{-}$, and 339 $[485-146]^{-}$. On acidic hydrolysis, 10 afforded monosaccharide fraction, which was converted into thiocarbamoyl-thiazolidine derivatives and then analyzed using HPLC, according to the process reported by Tanaka et al. ${ }^{20)}$ Derivatives of D-glucose, D-fucose, D-qinovose, and L-rhamnose were detected. The ${ }^{1} \mathrm{H}$ - and ${ }^{13} \mathrm{C}-\mathrm{NMR}$ signals of $\mathbf{1 0}$ were assigned with the aid of 2D-NMR spectra (Tables 3,4); the assigned data of the sugar moiety of $\mathbf{1 0}$ were quite similar to those of quamoclinic acid $\mathrm{C}^{14)}$ except that the data for the $\beta$-D-fucopyranosyl unit attached to the aglycone of quamoclinic acid $\mathrm{C}$ were replaced by those for the $\alpha$-D-fucopyranosyl unit. From these data, the structure of $\mathbf{1 0}$ was considered to be methyl $\beta$-Dquinovopyranosyl-( $1 \rightarrow 2)-O$ - $\beta$-D-glucopyranosyl- $(1 \rightarrow 3)$ - $[O$ $\beta$-D-quinovopyranosyl-( $1 \rightarrow 4)]$ - $O$ - $\alpha$-L-rhamnopyranosyl- $(1 \rightarrow$ $2)-O$ - $\beta$-D-glucopyranosyl-( $1 \rightarrow 2)-\alpha$-D-fucopyranoside (Fig. 2). This structure was confirmed by the following evidence. The ${ }^{13} \mathrm{C}$-NMR spectrum of $\mathbf{1 0}$ showed, compared with those of methyl pyranosides in the literature, ${ }^{21,22)}$ glycosylation shifts $^{23,24)}$ of the signals due to $\mathrm{C}-2(+9.2 \mathrm{ppm})$ of the first fucosyl unit (Fuc), C-2 (+3.8 ppm) of the first glucosyl unit (Glc), C-3 (+6.4 ppm) and C-4 (+5.4 ppm) of Rha, and C-2 $(+10.0 \mathrm{ppm})$ of the second glucosyl unit $\left(\mathrm{Glc}^{\prime}\right)$. In the HMBC spectrum of 10, key cross-peaks between $\mathrm{H}-1$ of Glc' and C-3 of Rha, H-1 of Qui and C-4 of Rha, H-1 of Qui' and C-2 of $\mathrm{Glc}^{\prime}$, and methoxy protons and $\mathrm{C}-1$ of Fuc, were observed.
A comparison of the ${ }^{1} \mathrm{H}-\mathrm{NMR}$ spectrum of $\mathbf{4}$ with that of $\mathbf{1 0}$ showed significant downfield shifts $[\Delta \delta=\delta(\mathbf{4})-\delta(\mathbf{1 0})]$ of the signals due to H-4 $(\Delta \delta=1.66)$ of Qui and H-4 $(\Delta \delta=1.55)$ of Qui' in 4. In addition, the HMBC spectrum of $\mathbf{4}$ showed key cross peaks between $\mathrm{H}-4$ of Qui and C-1 of Nla and H-4 of Qui' and $\mathrm{C}-1$ of the second niloyl unit $\left(\mathrm{Nla}^{\prime}\right)$ (Fig. 1). Accordingly, the structure of 4 was assigned as methyl (4-O-2R,3R-niloyl)$\beta$-D-quinovopyranosyl- $(1 \rightarrow 2)-O-\beta$-D-glucopyranosyl- $(1 \rightarrow$ $3)$-[O-(4-O-2R,3R-niloyl)- $\beta$-D-quinovopyranosyl-( $1 \rightarrow 4)]-O-\alpha$ L-rhamnopyranosyl- $(1 \rightarrow 2)-O$ - $\beta$-D-glucopyranosyl- $(1 \rightarrow 2)-\alpha$-Dfucopyranoside (Fig. 2).

QM-5 (5) was obtained as an amorphous powder. Alkaline hydrolysis of 5 gave nilic acid, 7, and 10. The positive-ion FAB-MS of 5 revealed a $[\mathrm{M}+\mathrm{Na}]^{+}$ion peak at $\mathrm{m} / \mathrm{z} 1479$, which was 316 mass units larger than that of 4 . The molecular formula of 5 was found to be $\mathrm{C}_{63} \mathrm{H}_{108} \mathrm{O}_{37}$ using HR-positiveion FAB-MS. The ${ }^{1} \mathrm{H}$ - and ${ }^{13} \mathrm{C}-\mathrm{NMR}$ spectra of $\mathbf{5}$ were imposable on those of $\mathbf{4}$, apart from the appearance of signals due to one QaB (Tables 3, 4). A comparison of the chemical shifts of the signals in $\mathbf{4}$ and $\mathbf{5}$ showed a significant downfield shift (1.17 ppm) of the signal assignable to $\mathrm{H}-2$ of Rha of 5; in contrast, the signals due to H-4 of Qui and H-4 of Qui' resonated at similar chemical shifts to those of 4 . These data suggest that $\mathbf{5}$ is a derivative of $\mathbf{4}$, in which $\mathbf{7}$ is attached to $\mathrm{OH}-2$ of Rha of 4. This inference was supported by the following evidence. Partial deacylation of $\mathbf{5}$ in a similar manner to that performed on 2 gave 11. A comparison of the ${ }^{1} \mathrm{H}-\mathrm{NMR}$ signals of 5 and 11 showed two significant upfield shifts $[\Delta \delta=\delta(\mathbf{5})-\delta(\mathbf{1 1})]$ of the signals due to H-4 $(\Delta \delta=1.65)$ of Qui and H-4 $(\Delta \delta=$ 1.60) of Qui' and the disappearance of the signals due to the two niloyl units in the spectrum of 11; the signal due to $\mathrm{H}-2$ of Rha in $\mathbf{1 1}$ resonated at a similar position to that in $\mathbf{5}$ (Tables 3, 4). The HMBC spectrum of $\mathbf{5}$ indicated key correlations between $\mathrm{H}-4$ of Qui or H-4 of Qui' and C-1 of Nla and H-4 of Qui' or H-4 of Qui and C-1 of Nla' (Fig. 1). Consequently, the structures of $\mathbf{5}$ and $\mathbf{1 1}$ were respectively identified as methyl (4- $O-2 R, 3 R$-niloyl)- $\beta$-D-quinovopyranosyl-( $1 \rightarrow$ 
Table 2. ${ }^{13} \mathrm{C}-\mathrm{NMR}$ Spectral Data for $\mathbf{1}-\mathbf{3}$ and $\mathbf{8}$ (in Pyridine- $d_{5}, 125 \mathrm{MHz}$ )

\begin{tabular}{|c|c|c|c|c|c|c|c|c|c|}
\hline Position & 1 & 2 & 8 & 3 & & 1 & 2 & 8 & 3 \\
\hline Fuc-1 & 102.5 & 102.4 & 102.4 & 102.6 & Qui-1 & 102.1 & 101.8 & 102.0 & \\
\hline 2 & 78.6 & 78.5 & 78.6 & 78.6 & 2 & 76.3 & 76.3 & 76.6 & \\
\hline 3 & 76.1 & 76.0 & 76.2 & 76.0 & 3 & 75.8 & 75.8 & 78.4 & \\
\hline 4 & 72.9 & 73.1 & 73.1 & 73.4 & 4 & 77.5 & 77.5 & 77.0 & \\
\hline 5 & 71.0 & 71.0 & 71.0 & 71.0 & 5 & 69.8 & 70.0 & 72.5 & \\
\hline 6 & 17.1 & 17.1 & 17.1 & 17.0 & 6 & 18.6 & 18.6 & 18.6 & \\
\hline Fuc' $^{\prime}-1$ & & & & 102.2 & Qui'-1 & 106.1 & 106.8 & 106.6 & 106.1 \\
\hline 2 & & & & 73.8 & 2 & 77.9 & 77.7 & 77.6 & 77.8 \\
\hline 3 & & & & 72.7 & 3 & 79.0 & 79.1 & 79.1 & 84.8 \\
\hline 4 & & & & 74.3 & 4 & 74.4 & 74.5 & 74.6 & 74.6 \\
\hline 5 & & & & 69.2 & 5 & 71.3 & 71.4 & 71.7 & 71.5 \\
\hline 6 & & & & 16.7 & 6 & 18.1 & 18.2 & 18.4 & 18.3 \\
\hline Fuc"-1 & & & & 107.1 & Nla-1 & 175.4 & 175.4 & & 174.9 \\
\hline 2 & & & & 73.5 & 2 & 48.4 & 48.4 & & 50.3 \\
\hline 3 & & & & 75.2 & 3 & 69.6 & 69.7 & & 69.7 \\
\hline 4 & & & & 72.7 & 4 & 21.1 & 21.2 & & 20.8 \\
\hline 5 & & & & 71.7 & 5 & 13.4 & 13.5 & & 14.2 \\
\hline 6 & & & & 17.1 & Tig'-1 & 167.1 & 167.2 & 167.1 & 167.3 \\
\hline Glc-1 & 102.3 & 102.2 & 102.0 & 102.2 & 2 & 128.9 & 128.9 & 129.0 & 129.0 \\
\hline 2 & 77.3 & 76.9 & 76.9 & 76.6 & 3 & 138.0 & 138.1 & 138.0 & 137.6 \\
\hline 3 & 79.0 & 78.6 & 78.2 & 78.6 & 4 & 14.3 & 14.4 & 14.5 & 14.2 \\
\hline 4 & 72.4 & 72.5 & 72.3 & 72.5 & 5 & 12.4 & 12.4 & 12.5 & 12.5 \\
\hline 5 & 77.2 & 77.2 & 77.3 & 77.2 & QaB-1 & & 173.3 & 173.3 & 173.4 \\
\hline 6 & 63.0 & 63.0 & 63.0 & 63.0 & 2 & & 34.7 & 34.7 & 34.7 \\
\hline $\mathrm{Glc}^{\prime}-1$ & 101.6 & 101.8 & 101.7 & 101.5 & 7 & & 78.8 & 78.9 & 78.6 \\
\hline 2 & 85.7 & 86.3 & 86.0 & 86.3 & 10 & & 14.4 & 14.4 & 14.4 \\
\hline 3 & 77.4 & 77.3 & 77.3 & 77.4 & Qui"-1 & & 103.4 & 103.4 & 103.4 \\
\hline 4 & 72.0 & 71.8 & 72.1 & 71.8 & 2 & & 75.6 & 75.6 & 75.6 \\
\hline 5 & 78.2 & 78.2 & 78.2 & 78.2 & 3 & & 78.2 & 78.2 & 78.2 \\
\hline 6 & 62.7 & 62.6 & 62.7 & 62.6 & 4 & & 76.9 & 76.9 & 76.9 \\
\hline Rha-1 & 101.0 & 97.4 & 97.2 & 97.6 & 5 & & 72.7 & 72.7 & 72.7 \\
\hline 2 & 72.0 & 74.1 & 74.1 & 73.9 & 6 & & 18.8 & 18.8 & 18.7 \\
\hline 3 & 77.9 & 75.3 & 74.5 & 75.2 & Agl-1 & 172.9 & 172.9 & 172.9 & 172.9 \\
\hline 4 & 79.5 & 79.3 & 79.8 & 79.3 & 2 & 43.4 & 43.4 & 43.4 & 43.4 \\
\hline 5 & 68.1 & 67.7 & 68.0 & 67.9 & 3 & 68.2 & 68.2 & 68.2 & 68.2 \\
\hline 6 & 19.2 & 19.1 & 19.2 & 19.1 & 11 & 80.0 & 80.1 & 80.2 & 80.2 \\
\hline Rha'-1 & 102.2 & 102.2 & 102.3 & & 14 & 14.4 & 14.5 & 14.5 & 14.5 \\
\hline 2 & 72.3 & 72.3 & 72.3 & & $\mathrm{OCH}_{3}$ & 51.2 & 51.3 & 51.2 & 51.2 \\
\hline 3 & 72.3 & 72.3 & 72.4 & & & & & & \\
\hline 4 & 73.7 & 73.7 & 73.7 & & & & & & \\
\hline 5 & 69.9 & 69.9 & 70.0 & & & & & & \\
\hline 6 & 18.8 & 18.7 & 18.7 & & & & & & \\
\hline
\end{tabular}

$\delta$ in ppm from TMS.

2)- $O$ - $\beta$-D-glucopyranosyl-(1 $\rightarrow 3)$-[O-(4-O-2R,3R-niloyl)- $\beta$-Dquinovopyranosyl- $(1 \rightarrow 4)]-O-(2-O-7 S$-hydroxydecanoyl $\quad 7-O-$ $\beta$-D-quinovopyranoside)- $\alpha$-L-rhamnopyranosyl-( $1 \rightarrow 2)-O-\beta$-Dglucopyranosyl-( $1 \rightarrow 2)-\alpha$-D-fucopyranoside, and its deacyl derivative, in which two niloyl units of $\mathbf{5}$ were cleaved (Fig. 2).

Mannich and Schumann ${ }^{10)}$ speculated that convolvulin from I. purga was an oligomer of acylated glycosidic acid. Although QM-2 and QM-3 were acylated by one quamoclinic acid B, QM-1, QM-2, and QM-3 were all regarded as methyl ester monomers of acylated glycosidic acid. On the other hand, both of QM-4 and QM-5 were acylated methyl glycosides. Two acylated trisaccharides, which are closely related resin glycosides, were previously reported as natural constituents of the seeds of Cuscuta chinensis. ${ }^{25)}$ Therefore, QM-4 and QM-5 were considered to be formed from the corresponding acylated saccharides with a reducing terminal during the treatment with indium(III) chloride in $\mathrm{MeOH}$. It is therefore presumed that one of the reasons for the difficulty in isolating convolvulin from the methanol extract of $Q$. pennata is the co-existence of the acylated saccharides with a reducing terminal, because $\alpha$ - and $\beta$-anomers easily reach equilibrium. ${ }^{25}$ ) Although QM-1-QM-5 were all considered to be artifacts formed during the treatment, they gave the new information of the structures of genuine convolvulins of $Q$. pennata.

\section{Experimental}

General Procedures Optical rotations were determined with a JASCO P-1020 polarimeter. The ${ }^{1} \mathrm{H}-$ and ${ }^{13} \mathrm{C}-\mathrm{NMR}$ spectra were recorded by using a JEOL ECA-500 spectrometer, and chemical shifts are given on a $\delta(\mathrm{ppm})$ scale with 

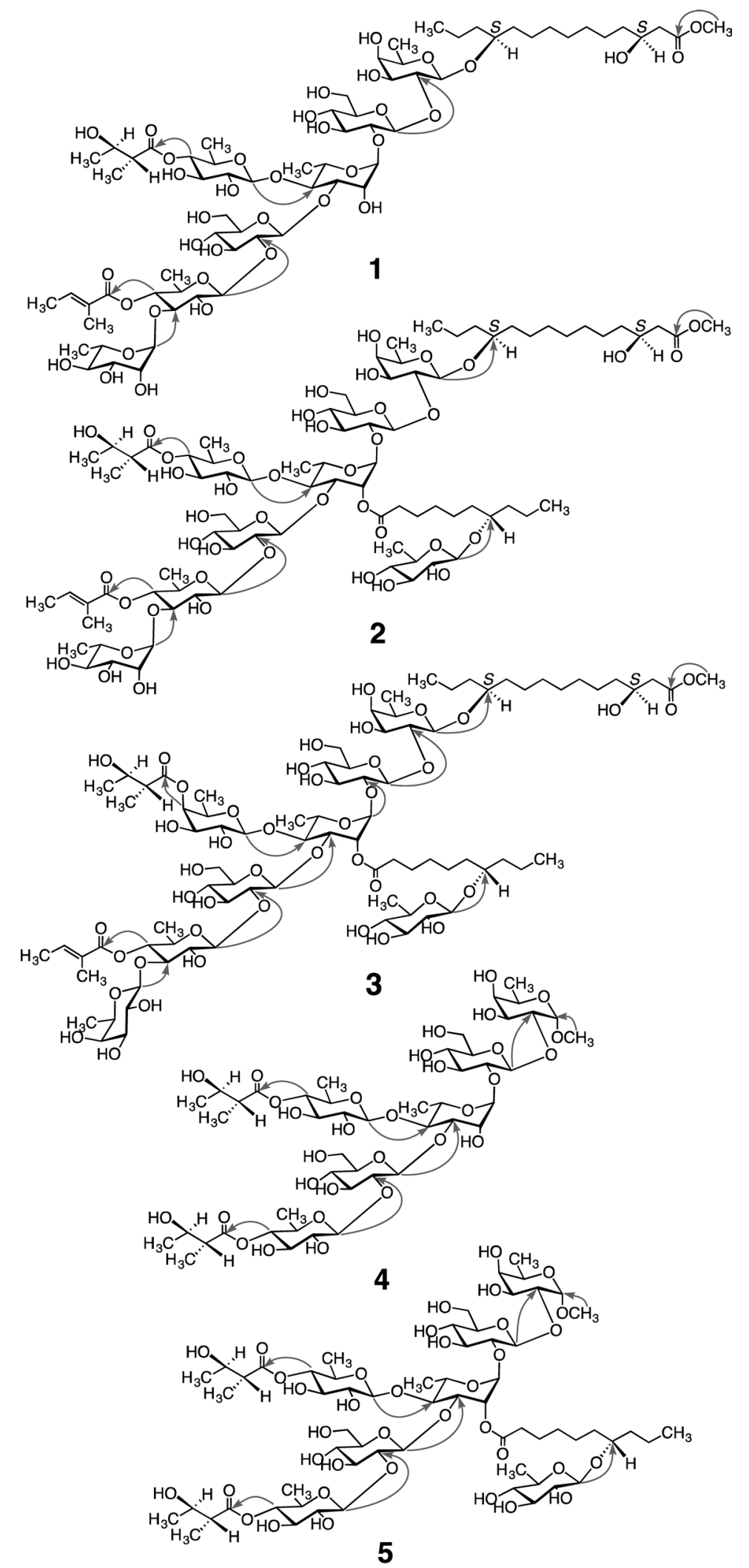

HMBC: $\mathrm{H}^{\top} \mathrm{C}$

Fig. 1. ${ }^{1} \mathrm{H}-{ }^{13} \mathrm{C}$ Long-Range Correlations Observed in the HMBC Spectra of $\mathbf{1}-\mathbf{5}$ (in Pyridine- $d_{5}, 500 \mathrm{MHz}$ )

tetramethylsilane (TMS) as an internal standard. MS data were collected using a JEOL JMS-700 mass spectrometer. Analytical GC was carried out with a Shimadzu GC-8A gas chromatograph with a flame-ionization detector. Colum chromatography (CC) was carried out over Diaion HP20 (Mitsubishi Chemical Industries, Japan), Sephadex LH-20 


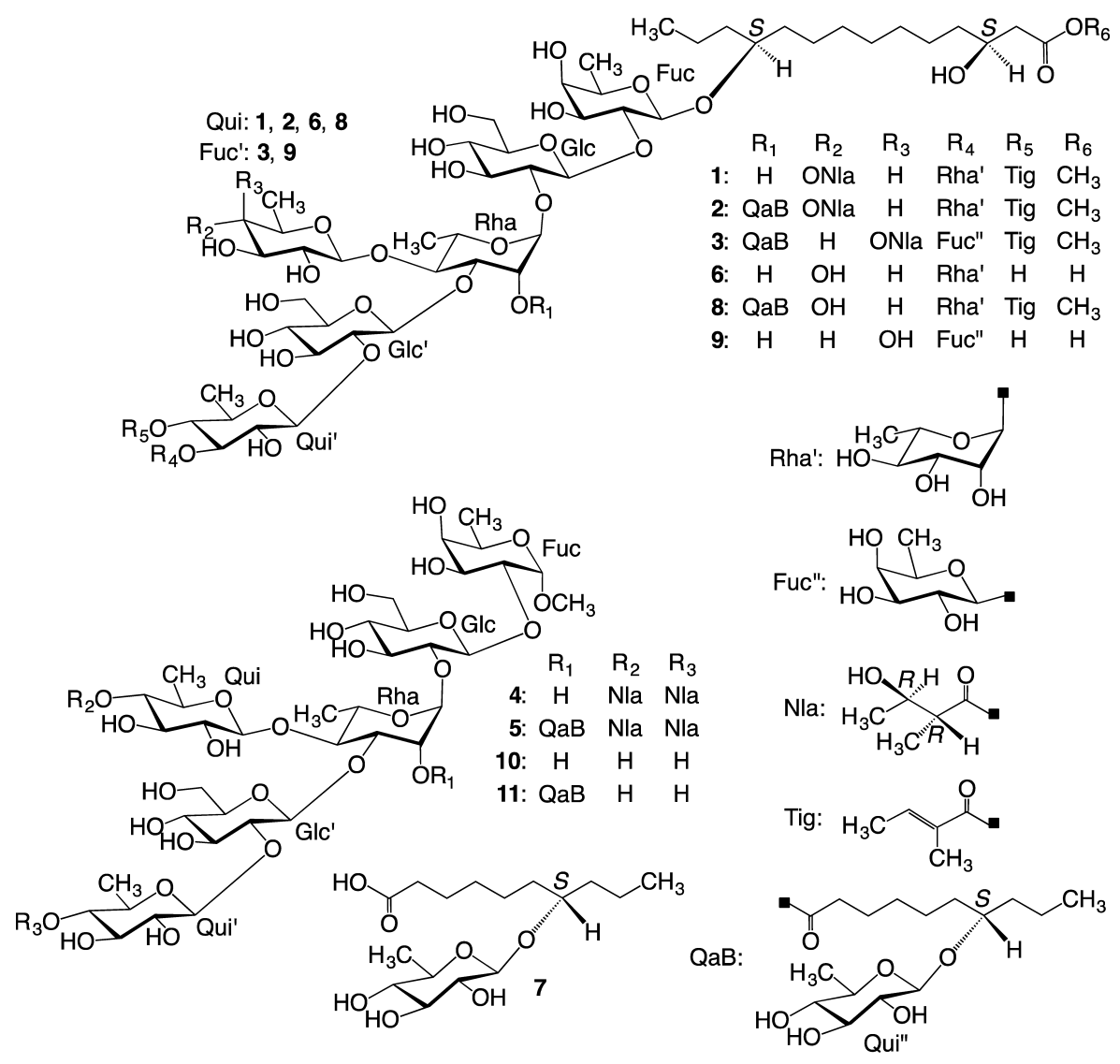

Fig. 2. Structures of $\mathbf{1}-\mathbf{5}$

(Pharmacia Fine Chemicals), silica gel 60 (Merck, Art. No. 1.09385), and Chromatorex ODS (Fuji Silysia Chemical, Ltd., Japan). HPLC separation was performed on a Shimadzu LC10AS micro pump with a Shimadzu RID-10A RI detector. For HPLC column chromatography, COSMOSIL 5C18-AR-II (Nacalai Tesque, Inc., Japan, $20 \mathrm{~mm}$ i.d. $\times 250 \mathrm{~mm}$, column 1) and COSMOSIL 5C18-AR (Nacalai Tesque, Inc., $6.0 \mathrm{~mm}$ i.d. $\times 250 \mathrm{~mm}$, column 2) were used.

Plant Material The seeds of Quamoclit pennata BOJER were purchased from Heiwaen, a gardening shop in Nara Prefecture, Japan, and were identified by Prof. Kazumoto Miyahara (Faculty of Pharmaceutical Sciences, Setsunan University). A voucher specimen (QP1990) has been deposited at the laboratory of Natural Products Chemistry, School of Agriculture, Tokai University.

Treatment of the Convolvulin Fraction with Indium(III) Chloride in $\mathrm{MeOH}$ and Isolation of 1-5 The crude covolvulin fraction $\left(15032 \mathrm{mg}\right.$ ) previously obtained ${ }^{18)}$ from the seeds of Quamoclit pennata was dissolved in $\mathrm{MeOH}(300 \mathrm{~mL})$, and indium(III) chloride $(7500 \mathrm{mg})$ was added to the solution at the room temperature. The mixture was heated at reflux for $27 \mathrm{~d}$, while being monitored by TLC. The concentrated reaction mixture was chromatographed on a Diaion HP20 column, eluted with $\mathrm{H}_{2} \mathrm{O}$ and $\mathrm{MeOH}$. The $\mathrm{MeOH}$ eluate (11162 mg) was subjected to Sephadex LH-20 CC eluted with $\mathrm{MeOH}$ to give fractions $1(1630 \mathrm{mg})$ and $2(8113 \mathrm{mg})$. CC of fraction 2 on silica gel eluted with a gradient of mixtures of $\mathrm{CHCl}_{3}-\mathrm{MeOH}-$ $\mathrm{H}_{2} \mathrm{O}(14: 2: 0.1,10: 2: 0.1,8: 2: 0.2,7: 3: 0.5,6: 4: 1,0: 1: 0)$ afforded fractions $2.1-2.15$. Fraction $2.10(2142 \mathrm{mg})$ was chromatographed on a Chromatorex ODS column using a gradient of mixtures of $\mathrm{MeOH}-\mathrm{H}_{2} \mathrm{O}(60 \% \mathrm{MeOH}, 70 \% \mathrm{MeOH}, 80 \%$ $\mathrm{MeOH}, 85 \% \mathrm{MeOH}, 90 \% \mathrm{MeOH}, 100 \% \mathrm{MeOH})$ as eluents to give fractions 2.10.1-2.10.18. HPLC (column 1) of fractions $2.10 .11(140 \mathrm{mg}$ ) and $2.10 .14(355 \mathrm{mg})$, using $85 \% \mathrm{MeOH}$ as eluent, afforded $\mathbf{1}(25 \mathrm{mg})$ from fraction 2.10 .11 and $2(131 \mathrm{mg})$ and $3(73 \mathrm{mg})$ from fraction 2.10.14. Fraction $2.11(2666 \mathrm{mg})$ was chromatographed on a Chromatorex ODS column using a gradient of mixtures of $\mathrm{MeOH}-\mathrm{H}_{2} \mathrm{O}(60 \% \mathrm{MeOH}, 65 \%$ $\mathrm{MeOH}, 70 \% \mathrm{MeOH}, 75 \% \mathrm{MeOH}, 80 \% \mathrm{MeOH}, 85 \% \mathrm{MeOH}$, $90 \% \mathrm{MeOH}, 95 \% \mathrm{MeOH}, 100 \% \mathrm{MeOH})$ as eluents to give fractions 2.11.1-2.11.38. Fractions $2.11 .4(40 \mathrm{mg})$ and 2.11.16 $(108 \mathrm{mg}$ ) were each subjected to HPLC (column 1) using $60 \%$ $\mathrm{MeOH}$ for fraction 2.11.4 and $75 \% \mathrm{MeOH}$ for fraction 2.11.16 as eluents to give $\mathbf{4}(20 \mathrm{mg})$ from fraction 2.11 .4 and $\mathbf{5}(37 \mathrm{mg})$ from fraction 2.11.16.

QM-1 (1): Amorphous powder. $[\alpha]_{\mathrm{D}}^{26}-49.7^{\circ}(c=0.8, \mathrm{MeOH})$. Positive-ion FAB-MS $m / z$ : $1533[\mathrm{M}+\mathrm{Na}]^{+}$. HR-positive-ion FAB-MS m/z: 1533.6923 (Calcd for $\mathrm{C}_{67} \mathrm{H}_{114} \mathrm{O}_{37} \mathrm{Na}^{+}, 1533.6931$ ). Negative-ion FAB-MS m/z: $1509[\mathrm{M}-\mathrm{H}]^{-} .{ }^{1} \mathrm{H}-\mathrm{NMR}$ spectral data: see Table $1 .{ }^{13} \mathrm{C}$-NMR spectral data: see Table 2.

QM-2 (2): Amorphous powder. $[\alpha]_{\mathrm{D}}^{19}-48.1^{\circ}(c=1.6, \mathrm{MeOH})$. Positive-ion FAB-MS $m / z$ : $1849[\mathrm{M}+\mathrm{Na}]^{+}$. HR-positive-ion FAB-MS $m / z$ : 1849.8843 (Calcd for $\mathrm{C}_{83} \mathrm{H}_{142} \mathrm{O}_{43} \mathrm{Na}^{+}, 1849.8817$ ). ${ }^{1} \mathrm{H}-\mathrm{NMR}$ spectral data: see Table $1 .{ }^{13} \mathrm{C}-\mathrm{NMR}$ spectral data: see Table 2.

QM-3 (3): Amorphous powder. $[\alpha]_{\mathrm{D}}^{26}-34.1^{\circ}(c=0.7, \mathrm{MeOH})$. Positive-ion FAB-MS $m / z: 1849[\mathrm{M}+\mathrm{Na}]^{+}$. HR-positive-ion FAB-MS $m / z$ : 1849.8816 (Calcd for $\mathrm{C}_{83} \mathrm{H}_{142} \mathrm{O}_{43} \mathrm{Na}^{+}, 1849.8817$ ). Negative-ion FAB-MS $m / z$ : $1825[\mathrm{M}-\mathrm{H}]^{-}, 333$ [quamoclinic acid $\mathrm{B}-\mathrm{H}]^{-}$. ${ }^{1} \mathrm{H}-\mathrm{NMR}$ spectral data: see Table $1 .{ }^{13} \mathrm{C}-\mathrm{NMR}$ 
Table 3. $\quad{ }^{1} \mathrm{H}-\mathrm{NMR}$ Spectral Data for 4, 5, 10, and 11 (in Pyridine- $d_{5}, 500 \mathrm{MHz}$ )

\begin{tabular}{|c|c|c|c|c|}
\hline Position & 4 & 10 & 5 & 11 \\
\hline Fuc-1 & $5.31 \mathrm{~d}(3.0)$ & $5.30 \mathrm{~d}(3.5)$ & $5.30 \mathrm{~d}(3.0)$ & $5.30 \mathrm{~d}(3.5)$ \\
\hline 2 & $4.48 \mathrm{dd}(3.0,10.0)$ & $4.50 \mathrm{dd}(3.5,10.5)$ & $4.46 \mathrm{dd}(3.0,9,5)$ & $4.48 \mathrm{dd}(3.5,10.5)$ \\
\hline 3 & $4.56 \mathrm{dd}(3.0,10.0)$ & $4.57 \mathrm{dd}(3.5,10.5)$ & $4.59 \mathrm{dd}(3.0,9.5)$ & $4.60 \mathrm{dd}(3.5,10.5)$ \\
\hline 4 & $4.05 \mathrm{~d}(3.0)$ & $4.07^{a)}$ & $4.07 \mathrm{~d}(3.0)$ & $4.09 \mathrm{~d}(3.5)$ \\
\hline 5 & $4.02 \mathrm{~m}$ & $4.00^{a)}$ & $4.03^{a)}$ & $4.00^{a)}$ \\
\hline 6 & $1.40 \mathrm{~d}(7.0)$ & $1.40 \mathrm{~d}(6.5)$ & $1.36 \mathrm{~d}(7.0)$ & $1.38 \mathrm{~d}(6.5)$ \\
\hline Glc-1 & $4.96^{b)}$ & $5.01 \mathrm{~d}(7.0)$ & $4.93 \mathrm{~d}(7.5)$ & $4.96^{a)}$ \\
\hline 2 & $4.08^{a)}$ & $4.11^{a)}$ & $4.16 \mathrm{dd}(7.5,9.0)$ & $4.18^{a)}$ \\
\hline 3 & $4.08^{a)}$ & $4.08^{a)}$ & $4.04^{a)}$ & $4.06^{a)}$ \\
\hline 4 & $4.08^{a)}$ & $4.08^{a)}$ & $4.04^{a}$ & $4.06^{a)}$ \\
\hline 5 & $3.61 \mathrm{~m}$ & $3.62 \mathrm{~m}$ & $3.56 \mathrm{~m}$ & $3.59 \mathrm{~m}$ \\
\hline 6 & $4.35 \mathrm{dd}(4.0,12.0)$ & $4.36^{a)}$ & $4.33 \mathrm{dd}(2.5,11.5)$ & $4.35^{a)}$ \\
\hline 6 & $4.26 \mathrm{dd}(5.0,12.0)$ & $4.26 \mathrm{dd}(5.0,11.5)$ & $4.24 \mathrm{dd}(5.0,11.5)$ & $4.26 \mathrm{dd}(5.0,11.5)$ \\
\hline Glc'-1 & $5.97 \mathrm{~d}(8.0)$ & $5.90 \mathrm{~d}(8.0)$ & $5.89 \mathrm{~d}(8.0)$ & $5.90 \mathrm{~d}(8.0)$ \\
\hline 2 & $3.92 \mathrm{dd}(8.0,9.0)$ & $3.97 \mathrm{dd}(8.0,9.5)$ & $3.97 \mathrm{dd}(8.0,8.5)$ & $3.97 \mathrm{dd}(8.0,9.5)$ \\
\hline 3 & $4.38 \mathrm{dd}(9.0,9.0)$ & $4.37^{a)}$ & $4.30^{a)}$ & $4.34^{a)}$ \\
\hline 4 & $4.13 \mathrm{dd}(9.0,9.0)$ & $4.11^{a)}$ & $4.04^{a)}$ & $4.06^{a)}$ \\
\hline 5 & $3.87 \mathrm{~m}$ & 3.88 ddd $(3.0,5.5,9.5)$ & $3.80 \mathrm{~m}$ & $3.86^{a)}$ \\
\hline 6 & $4.36^{a)}$ & $4.39^{a)}$ & $4.32^{a)}$ & $4.37^{a)}$ \\
\hline 6 & $4.13^{a)}$ & $4.14 \mathrm{dd}(5.5,12.0)$ & $4.06^{a)}$ & $4.09^{a)}$ \\
\hline Rha-1 & $6.17 \mathrm{~s}$ & $6.20 \mathrm{~d}(1.5)$ & $6.16 \mathrm{~s}$ & $6.19 \mathrm{~d}(2.0)$ \\
\hline 2 & $4.92 \mathrm{~d}(3.0)$ & $4.94 \mathrm{dd}(1.5,3.0)$ & $6.11 \mathrm{~d}(3.5)$ & $6.09 \mathrm{dd}(2.0,3.0)$ \\
\hline 3 & 5.16 dd $(3.0,9.0)$ & $5.17 \mathrm{dd}(3.0,9.0)$ & 5.36 dd $(3.5,9.0)$ & $5.40 \mathrm{dd}(3.0,9.0)$ \\
\hline 4 & $4.67 \mathrm{dd}(9.0,9.0)$ & $4.70 \mathrm{dd}(9.0,9.0)$ & $4.51 \mathrm{dd}(9.0,9.0)$ & $4.59 \mathrm{dd}(9.0,9.0)$ \\
\hline 5 & $4.90 \mathrm{dq}(9.0,6.0)$ & $4.95 \mathrm{dq}(9.0,6.0)$ & $5.00 \mathrm{dq}(9.0,6.0)$ & $5.01 \mathrm{dq}(9.0,6.5)$ \\
\hline 6 & $1.81 \mathrm{~d}(6.0)$ & $1.86 \mathrm{~d}(6.0)$ & $1.82 \mathrm{~d}(6.0)$ & $1.88 \mathrm{~d}(6.5)$ \\
\hline Qui-1 & $5.92 \mathrm{~d}(7.5)$ & $5.78 \mathrm{~d}(8.0)$ & $5.99 \mathrm{~d}(7.5)$ & $5.94 \mathrm{~d}(7.5)$ \\
\hline 2 & 3.97 dd $(7.5,9.0)$ & $3.95 \mathrm{dd}(8.0,9.0)$ & 3.97 dd $(7.5,9.0)$ & $4.01 \mathrm{dd}(7.5,9.0)$ \\
\hline 3 & $4.45 \mathrm{dd}(9.0,9.0)$ & $4.31 \mathrm{dd}(9.0,9.0)$ & $4.50 \mathrm{dd}(9.0,9.0)$ & $4.34^{a)}$ \\
\hline 4 & $5.34 \mathrm{dd}(9.0,9.0)$ & $3.68 \mathrm{dd}(9.0,9.0)$ & 5.37 dd $(9.0,9.0)$ & $3.72 \mathrm{dd}(9.0,9.0)$ \\
\hline 5 & $4.29 \mathrm{~m}$ & $4.04^{a)}$ & $4.43 \mathrm{~m}$ & $4.18^{a)}$ \\
\hline 6 & $1.53 \mathrm{~d}(6.5)$ & $1.56 \mathrm{~d}(6.5)$ & $1.63 \mathrm{~d}(6.0)$ & $1.64 \mathrm{~d}(6.5)$ \\
\hline Qui'-1 & $5.13 \mathrm{~d}(8.0)$ & $5.13 \mathrm{~d}(8.0)$ & $5.24 \mathrm{~d}(7.5)$ & $5.16 \mathrm{~d}(7.5)$ \\
\hline 2 & $4.19 \mathrm{dd}(8.0,9.0)$ & $4.17 \mathrm{dd}(8.0,9.0)$ & $4.26 \mathrm{dd}(7.5,9.0)$ & $4.17^{a)}$ \\
\hline 3 & $4.04 \mathrm{dd}(9.0,9.0)$ & $4.01^{a)}$ & $4.21 \mathrm{dd}(9.0,9.0)$ & $4.12 \mathrm{dd}(8.5,8.5)$ \\
\hline 4 & 5.29 dd $(9.0,9.0)$ & $3.74^{a)}$ & $5.37 \mathrm{dd}(9.0,9.0)$ & $3.77^{a)}$ \\
\hline 5 & $3.83 \mathrm{dq}(9.0,6.5)$ & $3.74^{a)}$ & $3.97 \mathrm{~m}$ & $3.85^{a)}$ \\
\hline 6 & $1.54 \mathrm{~d}(6.5)$ & $1.67^{a)}$ & $1.66 \mathrm{~d}(6.5)$ & $1.77 \mathrm{~d}(6.5)$ \\
\hline Nla-2 & $2.99 \mathrm{dq}(7.0,7.0)$ & & $3.02 \mathrm{dq}(7.0,7.0)$ & \\
\hline 3 & $4.36^{a)}$ & & $4.38 \mathrm{dq}(7.0,7.0)$ & \\
\hline 4 & $1.36 \mathrm{~d}(6.5)$ & & $1.38 \mathrm{~d}(7.0)$ & \\
\hline 5 & $1.31 \mathrm{~d}(7.0)$ & & $1.32 \mathrm{~d}(7.0)$ & \\
\hline $\mathrm{Nla}^{\prime}-2$ & $2.82 \mathrm{dq}(7.0,7.0)$ & & $2.87 \mathrm{dq}(7.0,7.0)$ & \\
\hline 3 & $4.30^{a)}$ & & $4.33^{a)}$ & \\
\hline 4 & $1.39 \mathrm{~d}(6.5)$ & & $1.41 \mathrm{~d}(6.5)$ & \\
\hline 5 & $1.28 \mathrm{~d}(7.0)$ & & $1.30 \mathrm{~d}(7.0)$ & \\
\hline QaB-2 & & & 2.47 ddd $(7.5,7.5,15.5)$ & 2.54 ddd $(7.0,8.5,16.0)$ \\
\hline 2 & & & 2.38 ddd $(7.5,7.5,15.5)$ & 2.40 ddd $(6.5,8.0,16.0)$ \\
\hline 7 & & & $3.88 \mathrm{~m}$ & $3.87^{a)}$ \\
\hline 10 & & & $0.94 \mathrm{t}(7.0)$ & $0.93 \mathrm{t}(7.0)$ \\
\hline Qui"-1 & & & $4.79 \mathrm{~d}(8.0)$ & $4.79 \mathrm{~d}(8.0)$ \\
\hline 2 & & & $3.96 \mathrm{dd}(8.0,9.0)$ & $3.96 \mathrm{dd}(8.0,9.0)$ \\
\hline 3 & & & $4.15 \mathrm{dd}(9.0,9.0)$ & $4.15 \mathrm{dd}(9.0,9.0)$ \\
\hline 4 & & & $3.71 \mathrm{dd}(9.0,9.0)$ & $3.71 \mathrm{dd}(9.0,9.0)$ \\
\hline 5 & & & $3.78 \mathrm{dq}(9.0,6.0)$ & $3.78^{a)}$ \\
\hline 6 & & & $1.62 \mathrm{~d}(6.0)$ & $1.62 \mathrm{~d}(6.0)$ \\
\hline $\mathrm{OCH}_{3}$ & $3.29 \mathrm{~s}$ & $3.28 \mathrm{~s}$ & $3.29 \mathrm{~s}$ & $3.28 \mathrm{~s}$ \\
\hline
\end{tabular}

$\delta$ in ppm from TMS. Coupling constants $(J)$ in $\mathrm{Hz}$ are given in parentheses. $a$ ) Signals were overlapped with other signals. $b$ ) Signals were deformed by virtual coupling. 
Table 4. ${ }^{13} \mathrm{C}$-NMR Spectral Data for 4, 5, 10, and $\mathbf{1 1}$ (in Pyridine- $d_{5}, 125 \mathrm{MHz}$ )

\begin{tabular}{|c|c|c|c|c|c|c|c|c|c|}
\hline Position & 4 & 10 & 5 & 11 & & 4 & 10 & 5 & 11 \\
\hline Fuc-1 & 100.9 & 100.9 & 100.8 & 100.8 & Qui'-1 & 106.2 & 105.5 & 106.4 & 105.8 \\
\hline 2 & 79.4 & 79.2 & 79.2 & 79.1 & 2 & 76.3 & 75.9 & 76.2 & 76.0 \\
\hline 3 & 70.0 & 70.1 & 70.0 & 70.1 & 3 & 75.3 & 78.0 & 75.3 & 77.9 \\
\hline 4 & 73.0 & 73.0 & 73.1 & 73.2 & 4 & 76.6 & 76.5 & 76.4 & 76.5 \\
\hline 5 & 66.5 & 66.5 & 66.5 & 66.5 & 5 & 71.2 & 73.8 & 71.0 & 74.0 \\
\hline 6 & 16.9 & 16.9 & 16.9 & 16.9 & 6 & 18.2 & 18.6 & 18.3 & 18.7 \\
\hline Glc-1 & 105.1 & 105.1 & 104.7 & 104.7 & Nla-1 & 175.4 & & 175.4 & \\
\hline 2 & 78.3 & 78.2 & 77.6 & 77.2 & 2 & 48.4 & & 48.3 & \\
\hline 3 & 78.5 & 78.6 & 78.4 & 78.5 & 3 & 69.7 & & 69.6 & \\
\hline 4 & 71.6 & 71.6 & 71.6 & 71.7 & 4 & 20.9 & & 20.8 & \\
\hline 5 & 78.0 & 77.9 & 77.9 & 78.0 & 5 & 13.2 & & 13.2 & \\
\hline 6 & 62.5 & 62.6 & 62.4 & 62.5 & $\mathrm{Nla}^{\prime}-1$ & 175.0 & & 175.1 & \\
\hline $\mathrm{Glc}^{\prime}-1$ & 101.7 & 101.4 & 101.7 & 101.6 & 2 & 48.5 & & 48.4 & \\
\hline 2 & 85.8 & 84.8 & 85.8 & 84.8 & 3 & 69.5 & & 69.4 & \\
\hline 3 & 77.5 & 77.5 & 77.5 & 77.5 & 4 & 21.0 & & 20.9 & \\
\hline 4 & 71.4 & 71.4 & 71.2 & 71.4 & 5 & 13.3 & & 13.3 & \\
\hline 5 & 78.0 & 78.2 & 78.1 & 78.2 & QaB-1 & & & 173.5 & 173.7 \\
\hline 6 & 62.5 & 62.5 & 62.3 & 62.5 & 2 & & & 34.7 & 34.7 \\
\hline Rha-1 & 101.4 & 101.4 & 98.0 & 98.0 & 7 & & & 78.4 & 78.8 \\
\hline 2 & 71.7 & 71.6 & 73.7 & 73.6 & 10 & & & 14.3 & 14.4 \\
\hline 3 & 79.0 & 79.0 & 76.2 & 75.8 & Qui"-1 & & & 103.3 & 103.4 \\
\hline 4 & 78.8 & 78.9 & 78.6 & 78.7 & 2 & & & 75.5 & 75.6 \\
\hline 5 & 68.4 & 68.7 & 67.9 & 68.3 & 3 & & & 78.1 & 78.2 \\
\hline 6 & 18.8 & 18.9 & 18.8 & 18.9 & 4 & & & 76.9 & 76.9 \\
\hline Qui-1 & 102.2 & 102.8 & 101.9 & 102.4 & 5 & & & 72.7 & 72.7 \\
\hline 2 & 76.2 & 76.6 & 76.2 & 76.6 & 6 & & & 18.6 & 18.7 \\
\hline 3 & 75.6 & 78.0 & 75.4 & 77.8 & $\mathrm{OCH}_{3}$ & 55.1 & 55.1 & 55.1 & 55.1 \\
\hline 4 & 77.7 & 77.3 & 77.8 & 77.3 & & & & & \\
\hline 5 & 69.9 & 72.3 & 69.9 & 72.4 & & & & & \\
\hline 6 & 18.2 & 18.5 & 18.2 & 18.6 & & & & & \\
\hline
\end{tabular}

$\delta$ in ppm from TMS.

spectral data: see Table 2 .

QM-4 (4): Amorphous powder. $[\alpha]_{\mathrm{D}}^{19}-26.5^{\circ}(c=1.4, \mathrm{MeOH})$. Positive-ion FAB-MS $m / z$ : $1163[\mathrm{M}+\mathrm{Na}]^{+}$. HR-positive-ion FAB-MS $m / z$ : 1163.4586 (Calcd for $\mathrm{C}_{47} \mathrm{H}_{80} \mathrm{O}_{31} \mathrm{Na}^{+}$, 1163.4576). Negative-ion FAB-MS $m / z$ : $1139[\mathrm{M}-\mathrm{H}]^{-}$. ${ }^{1} \mathrm{H}-\mathrm{NMR}$ spectral data: see Table $3 .{ }^{13} \mathrm{C}-\mathrm{NMR}$ spectral data: see Table 4.

QM-5 (5): Amorphous powder. $[\alpha]_{\mathrm{D}}^{19}-25.6^{\circ}(c=0.8, \mathrm{MeOH})$. Positive-ion FAB-MS $m / z$ : $1479[\mathrm{M}+\mathrm{Na}]^{+}$. HR-positive-ion FAB-MS $m / z$ : 1479.6472 (Calcd for $\mathrm{C}_{63} \mathrm{H}_{108} \mathrm{O}_{37} \mathrm{Na}^{+}, 1479.6462$ ). Negative-ion FAB-MS m/z: $1455[\mathrm{M}-\mathrm{H}]^{-} .{ }^{1} \mathrm{H}-\mathrm{NMR}$ spectral data: see Table $3 .{ }^{13} \mathrm{C}-\mathrm{NMR}$ spectral data: see Table 4.

Alkaline Hydrolysis of 1-5 Suspentions of $\mathbf{1}$ (4 $\mathrm{mg}), \mathbf{2}$ (10 mg), 3 (10 mg), 4 (10 mg), and 5 (5 mg) in $1 \mathrm{M} \mathrm{KOH}(1 \mathrm{~mL})$ were heated at $95^{\circ} \mathrm{C}$ for $1 \mathrm{~h}$. The reaction mixture was adjusted to $\mathrm{pH} 4$ with $1 \mathrm{M} \mathrm{HCl}$, then diluted with $\mathrm{H}_{2} \mathrm{O}(10 \mathrm{~mL})$, and extracted with ether $(99.5 \%$, Nacalai Tesque, Inc.; $3 \times 5 \mathrm{~mL})$. The ether layer was dried over $\mathrm{MgSO}_{4}$ and evaporated to furnish an organic acid fraction, which was analyzed by GC [Shimadzu GC-8A gas chromatograph with flame-ionaization detector; column, Unisole $30 \mathrm{~T}(5 \%), 3.2 \mathrm{~mm}$ i.d. $\times 2 \mathrm{~m}$ glass column (column 3); carrier gas $\mathrm{N}_{2}, 1.0 \mathrm{~kg} / \mathrm{cm}^{2}$; column temperature, $120^{\circ} \mathrm{C} ; t_{\mathrm{R}}(\mathrm{min})$ : 10.38 (tiglic acid) for $\mathbf{1}-\mathbf{3}$ ]. A part of the organic acid fraction was methylated with diazomethaneether and then the reaction mixture was analyzed by GC [column, column 3; column temperature, $100^{\circ} \mathrm{C}$; carrier gas, $\mathrm{N}_{2}$ $1.2 \mathrm{~kg} / \mathrm{cm}^{2} ; t_{\mathrm{R}}$ (min): 4.20 (methyl nilate) for $\mathbf{1}-\mathbf{5}$ ].

The aqueous layers of $\mathbf{1}-\mathbf{3}$ were each desalted over MCI gel
CHP 20 column chromatography using $\mathrm{H}_{2} \mathrm{O}$ and acetone as eluents to give glycosidic acid ( $3 \mathrm{mg}$ ) derived from $\mathbf{1}$ and glycosidic acid fractions ( $7 \mathrm{mg}$ from $2,7 \mathrm{mg}$ from 3 ) derived from $\mathbf{2}$ and 3. The glycosidic acid derived from $\mathbf{1}$ was identical with 6 by comparison of ${ }^{1} \mathrm{H}-\mathrm{NMR}$ spectrum with that of authentic sample. ${ }^{14)}$ The glycosidic acid fractions derived from 2 and 3 were each chromatographyied on silica gel column eluted with a gradient of mixtures of $\mathrm{CHCl}_{3}-\mathrm{MeOH}-\mathrm{H}_{2} \mathrm{O}(14: 2: 0.1$, $10: 2: 0.1,8: 2: 0.2,7: 3: 0.5,6: 4: 1,0: 1: 0)$ to afford $6(4 \mathrm{mg})$ and $7(1 \mathrm{mg})$ from the fraction derived from 2 and $7(1 \mathrm{mg})$ and $9(4 \mathrm{mg})$ from the fraction derived from 3 , which were identified by comparison of ${ }^{1} \mathrm{H}-\mathrm{NMR}$ spectra with those of authentic samples. ${ }^{14)}$

The aqueous layers of $\mathbf{4}$ and $\mathbf{5}$ were neutralized with $0.1 \mathrm{M}$ $\mathrm{NaOH}$. After removal of the solvent, the residues were subjected to Sephadex LH-20 CC eluted with $\mathrm{MeOH}$ to give $\mathbf{1 0}$ $(7 \mathrm{mg})$ from the residue derived from 4 and $7(0.5 \mathrm{mg})$ and $\mathbf{1 0}$ $(2 \mathrm{mg})$ from the residue derived from $\mathbf{5}$. The generated compounds derived from $\mathbf{5}$ were each identified by comparison of ${ }^{1} \mathrm{H}-\mathrm{NMR}$ spectra with those of authentic samples. ${ }^{14)}$

Methyl Quamoside A (10): Amorphous powder. $[\alpha]_{\mathrm{D}}^{24}-18.5^{\circ}$ $(c=1.3, \mathrm{MeOH})$. Positive-ion FAB-MS $m / z: 963[\mathrm{M}+\mathrm{Na}]^{+}$. HRpositive-ion FAB-MS m/z: 963.3569 (Calcd for $\mathrm{C}_{37} \mathrm{H}_{64} \mathrm{O}_{27} \mathrm{Na}^{+}$, 963.3527). Negative-ion FAB-MS $m / z: 939[\mathrm{M}-\mathrm{H}]^{-}, 793$ $[939-146]^{-}, 631\left[^{[793-162]^{-}, 485}[631-146]^{-}, 339\right.$ [485-146] $^{-}$. ${ }^{1} \mathrm{H}-\mathrm{NMR}$ spectral data: see Table $3 .{ }^{13} \mathrm{C}-\mathrm{NMR}$ spectral data: see Table 4. 
Partial Deacylation of 2 and 5 Solutions of 2 (32 mg) and $5(7 \mathrm{mg})$ in $5 \%$ triethylamine-MeOH $(1 \mathrm{~mL})$ were refluxed for $1 \mathrm{~h}$ and $2 \mathrm{~h}$, respectively. After removal of the solvent, the residues were successively subjected to silica gel $\mathrm{CC}$ eluted with a gradient of mixtures of $\mathrm{CHCl}_{3}-\mathrm{MeOH}-\mathrm{H}_{2} \mathrm{O}(14: 2: 0.1$, $10: 2: 0.1,8: 2: 0.2,7: 3: 0.5,6: 4: 1,0: 1: 0)$ and HPLC (column 2) using $85 \% \mathrm{MeOH}$ for residue derived from 2 and $70 \%$ $\mathrm{MeOH}$ for residue derived from 5 as eluents to give $8(15 \mathrm{mg})$ from the reaction mixture of $\mathbf{2}$ and $\mathbf{1 1}(4 \mathrm{mg})$ from the reaction mixture of $\mathbf{5}$.

Compound 8: Amorphous powder. $[\alpha]_{\mathrm{D}}^{25}-46.2^{\circ}(c=1.2$, $\mathrm{MeOH})$. Positive-ion FAB-MS $m / z: 1749[\mathrm{M}+\mathrm{Na}]^{+}$. HR-positive-ion FAB-MS $m / z$ : 1749.8273 (Calcd for $\mathrm{C}_{78} \mathrm{H}_{134} \mathrm{O}_{41} \mathrm{Na}^{+}$, 1749.8293). Negative-ion FAB-MS $m / z$ : $1725[\mathrm{M}-\mathrm{H}]^{-}, 333$. ${ }^{1} \mathrm{H}-\mathrm{NMR}$ spectral data: see Table $1 .{ }^{13} \mathrm{C}-\mathrm{NMR}$ spectral data: see Table 2 .

Compound 11: Amorphous powder. $[\alpha]_{\mathrm{D}}^{25}-22.9^{\circ}(c=0.5$, $\mathrm{MeOH})$. Positive-ion FAB-MS $m / z: 1279[\mathrm{M}+\mathrm{Na}]^{+}$. HRpositive-ion FAB-MS m/z: 1279.5419 (Calcd for $\mathrm{C}_{53} \mathrm{H}_{92} \mathrm{O}_{33} \mathrm{Na}^{+}$, 1279.5413). Negative-ion FAB-MS $m / z: 1255[\mathrm{M}-\mathrm{H}]^{-}$, $939[1255-316]^{-}, 793[939-146]^{-}, 631[793-162]^{-}, 485$ $[631-146]^{-}, 339[485-146]^{-}, 333 .{ }^{1} \mathrm{H}-\mathrm{NMR}$ spectral data: see Table $3 .{ }^{13} \mathrm{C}-\mathrm{NMR}$ spectral data: see Table 4.

Sugar Analysis of 7 Compound $7(1.0 \mathrm{mg})$ was heated in $1 \mathrm{M} \mathrm{HCl}(0.2 \mathrm{~mL})$ at $95^{\circ} \mathrm{C}$ for $1 \mathrm{~h}$. The reaction mixture was neutralized with Amberlite MB-3 (Organo Co.) and then evaporated under reduced pressure to give a monosaccharide fraction. This fraction was dissolved in pyridine $(0.2 \mathrm{~mL})$ containing L-cysteine methyl ester hydrochrolide $(1.0 \mathrm{mg})$ and heated at $60^{\circ} \mathrm{C}$ for $1 \mathrm{~h}$. A solution $(0.01 \mathrm{~mL})$ of $o$-tolylisothiocyanate $(0.1 \mathrm{~mL})$ in pyridine $(1.0 \mathrm{~mL})$ was added to the mixture, which was heated at $60^{\circ} \mathrm{C}$ for $1 \mathrm{~h}$. The reaction mixture was analyzed by HPLC [detector, Shimadzu SPD-10A UV detector $(250 \mathrm{~nm})$, column, column 2; eluent $25 \% \mathrm{CH}_{3} \mathrm{CN}$ in $50 \mathrm{~mm} \mathrm{H}_{3} \mathrm{PO}_{4}$; flow ate $0.8 \mathrm{~mL} / \mathrm{min}$; column temperature, $35^{\circ} \mathrm{C} ; t_{\mathrm{R}}$ (min): 27.39 (D-glucose deriv.), 36.91 (D-fucose deriv.), 42.09 (D-quinovose deriv.), 45.48 (L-rhamnose deriv.)].

Acknowledgments We express our appreciation to $\mathrm{Mr}$. H. Harazono of Fukuoka University for the measurement of the FAB-MS. The authors thank Prof. Kazumoto Miyahara (Faculty of Pharmaceutical Sciences, Setsunan University) for identifying the plant material.

\section{References}

1) Shellard E. J., Planta Med., 9, 102-116 (1961).

2) Mayer W., Justus Liebigs Ann. Chem., 95, 129-176 (1855).

3) Noda N., Ono M., Miyahara K., Kawasaki T., Okabe M., Tetrahedron, 43, 1389-3902 (1987).

4) Noda N., Tsuji K., Kawasaki T., Miyahara K., Nakazono H., Yang C.-R., Chem. Pharm. Bull., 43, 1061-1063 (1995).

5) Bah M., Pereda-Miranda R., Tetrahedron, 27, 9007-9022 (1997).

6) Escalante-Sánchez E., Pereda-Miranda R., J. Nat. Prod., 70, 10291034 (2007).

7) Castañeda-Gómez J., Pereda-Miranda R., J. Nat. Prod., 74, 1148 1153 (2011).

8) Rosas-Rameírez D., Escalante-Sánchez E., Pereda-Miranda R., Phytochemistry, 72, 773-780 (2011).

9) Castañeda-Gómez J., Figueroa-González G., Jacobo N., PeredaMiranda R., J. Nat. Prod., 76, 64-71 (2013).

10) Mannich C., Schumann P., Arch. Pharm., 276, 211-226 (1938).

11) MacLeod J. K., Ward A., Oelrichs P. B., J. Nat. Prod., 60, 467-471 (1997).

12) Pereda-Miranda R., Fragoso-Serrano M., Escalante-Sánchez E., Hernández-Carlos B., Linares E., Bye R., J. Nat. Prod., 69, 14601466 (2006).

13) Ono M., Nishioka H., Fukushima T., Kunimatsu H., Mine A., Kubo H., Miyahara K., Chem. Pharm. Bull., 57, 262-268 (2009).

14) Ono M., Takagi-Taki Y., Honda-Yamada F., Noda N., Miyahara K., Chem. Pharm. Bull., 58, 666-672 (2010).

15) Ono M., Imao M., Miyahara K., Chem. Pharm. Bull., 58, 1232-1235 (2010).

16) Ono M., Takigawa A., Mineno T., Yoshimitsu H., Nohara T., Ikeda T., Fukuda-Teramachi E., Noda N., Miyahara K., J. Nat. Prod., 73, 1846-1852 (2010).

17) Mineno T., Kansui H., Chem. Pharm. Bull., 54, 918-919 (2006).

18) Ono M., Kuwabata K., Kawasaki T., Miyahara K., Chem. Pharm. Bull., 40, 2674-2680 (1992).

19) Ono M., Takaki Y., Takatsuji M., Akiyama K., Okawa M., Kinjo J., Miyashita H., Yoshimitsu H., Nohara T., Chem. Pharm. Bull., 60, 1083-1087 (2012).

20) Tanaka T., Nakashima T., Ueda T., Tomii K., Kouno I., Chem. Pharm. Bull., 55, 899-901 (2007).

21) Kitagawa I., Nishio T., Kobayashi M., Kyogoku Y., Chem. Pharm. Bull., 29, 1951-1956 (1981).

22) Seo S., Tomita Y., Tori K., Yoshimura Y., J. Am. Chem. Soc., 100, 3331-3339 (1978).

23) Kasai R., Okihara M., Asakawa J., Tanaka O., Tetrahedron Lett., 18, 175-178 (1977).

24) Tori K., Seo S., Yoshimura Y., Arita H., Tomita Y., Tetrahedron Lett., 18, 179-182 (1977).

25) Miyahara K., Du X.-M., Watanabe M., Sugiura C., Yahara S., Nohara T., Chem. Pharm. Bull., 44, 481-485 (1996). 